Electronic Supplementary Information

\title{
Fluorescent and Opt-electric Recording Bacterial Identification Device for Ultra-sensitive and specific detection of microbials
}

Jiaomei Huanga,\#, Yongjie Zhong ${ }^{\mathrm{a}, \#}$, Wenxing Li ${ }^{\mathrm{a}, \#}$, Wenxia Wanga ${ }^{\mathrm{a}}$, Chaoyang Li ${ }^{\text {a }}$, Aimin Wanga , Hong Yan*a, Yi Wan*a, Jinghong Li ${ }^{\mathrm{b}, *}$

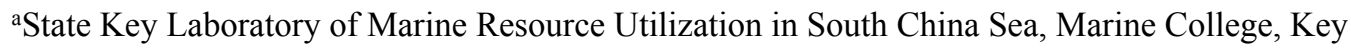

Laboratory of Tropical Biological Resources of Ministry of Education, School of Life and

Pharmaceutical Sciences, Hainan University, Haikou 570228, China

${ }^{b}$ Department of Chemistry, Key Laboratory of Bioorganic Phosphorus Chemistry \& Chemical Biology,

Tsinghua University, Beijing 100084, China 

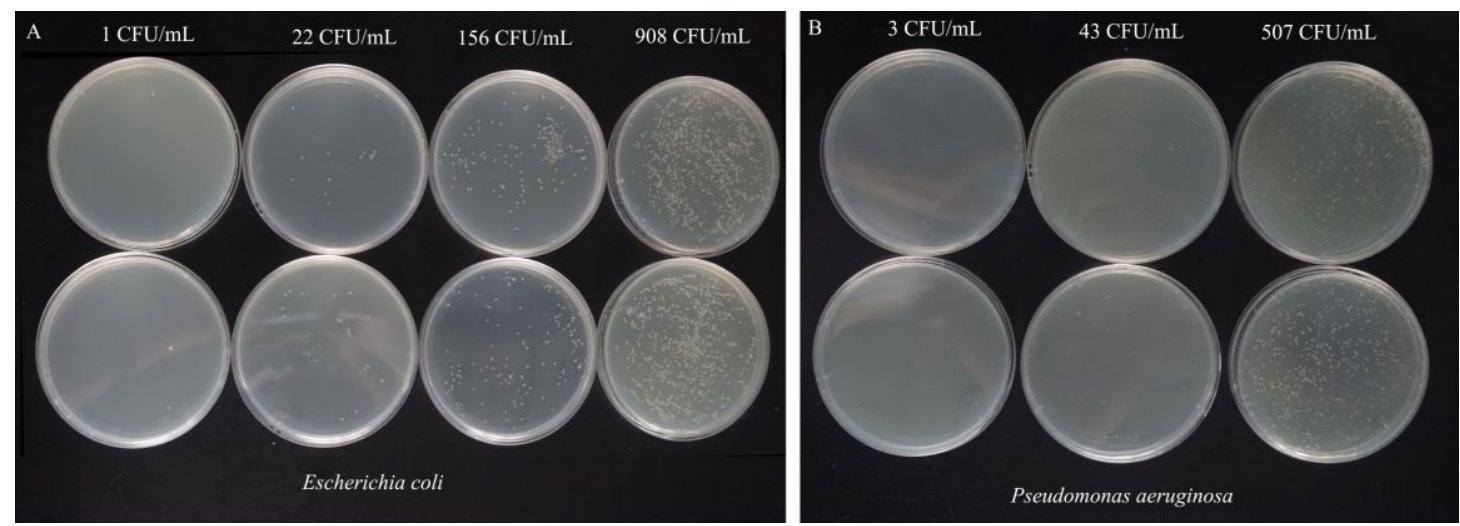

Fig. S1 Different concentration of (A) Escherichia coli and (B) Pseudomonas aeruginosa counted by plate count technique against FORBID technique in Figure 2. 


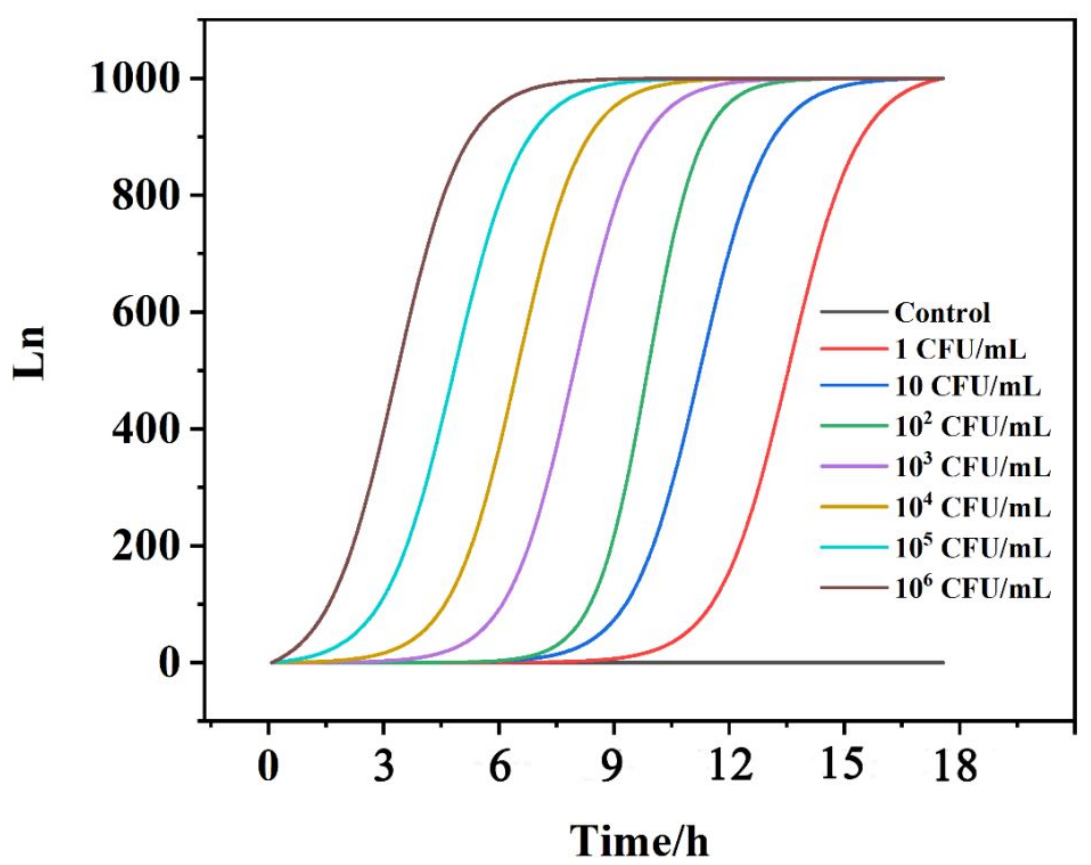

Fig. S2 E.coli in milk samples were detected by the microbiological assay system. 


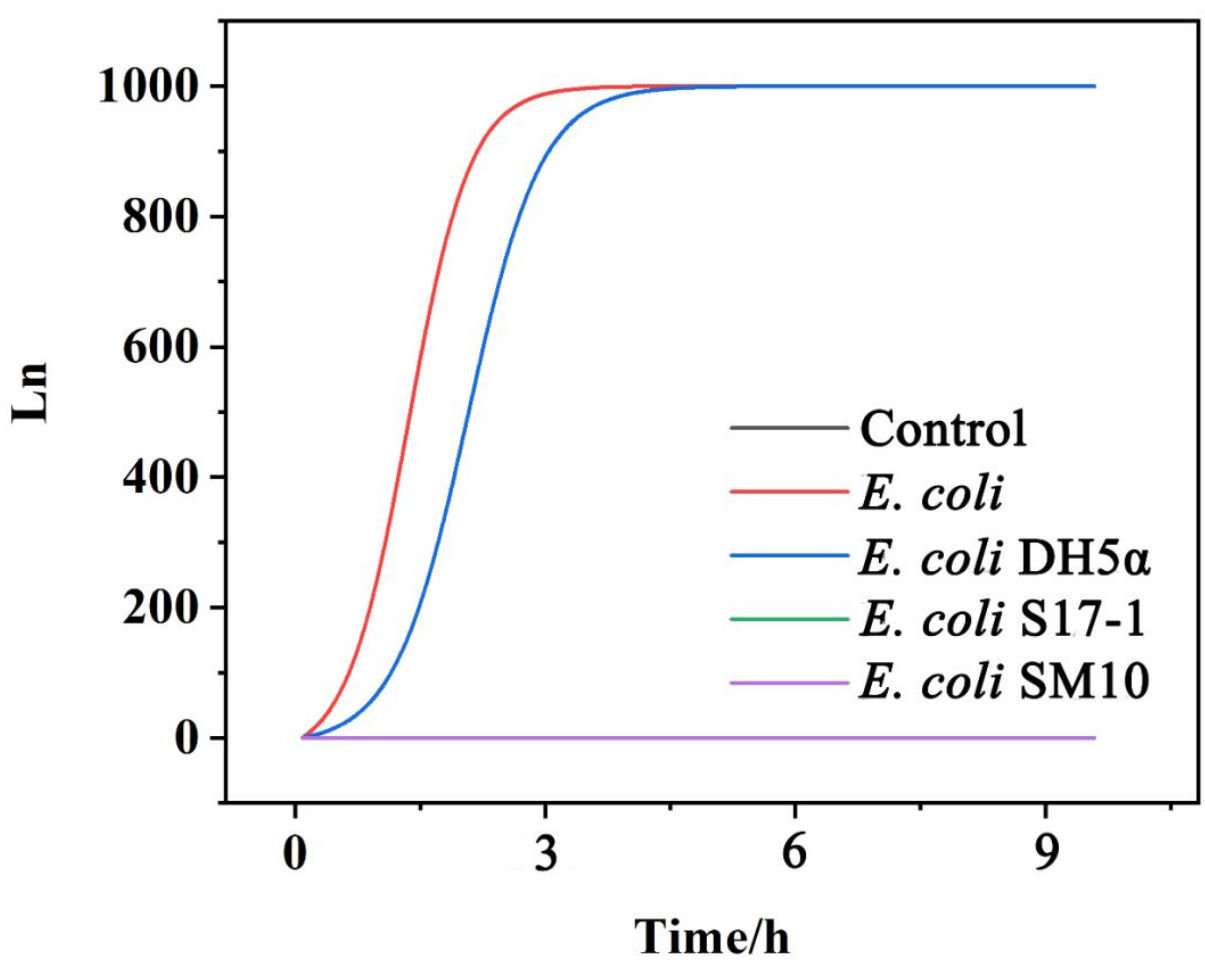

Fig. S3 Detection of the target different E.coli strains (E.coli, E.coli DH5a, E.coli SM10, and E.coli S17-1) by the microbiological assay system. 


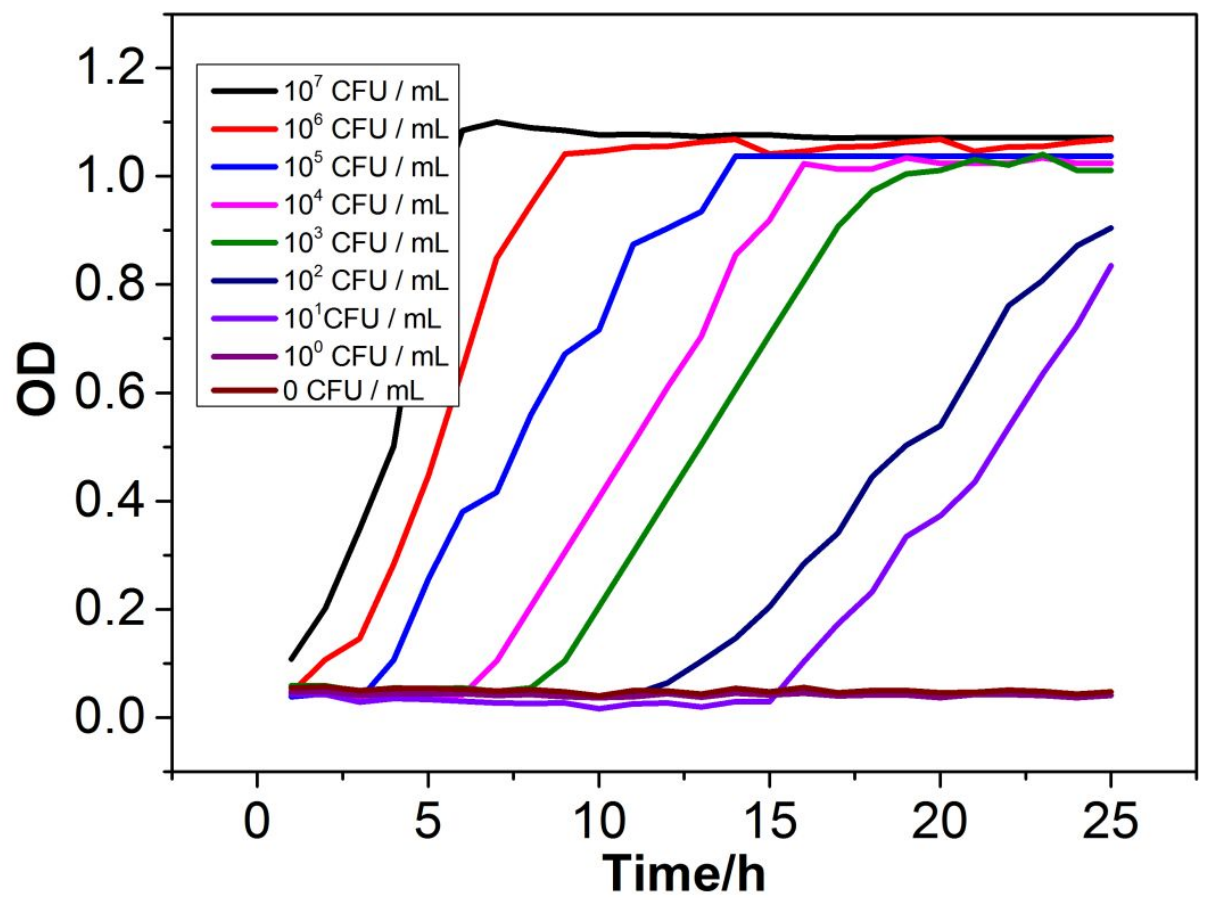

Fig. S4 Growth curve of the target different E.coli by the the Automatic Microbial Growth Analyzer (Bioscreen C MBR). 
Table S1 Recovery rates of bacterial detection using FORBID system from mix culture

\begin{tabular}{ccc}
\hline $\begin{array}{c}\text { Added bacteria } \\
(\mathrm{CFU} / \mathrm{mL})\end{array}$ & $\begin{array}{c}\text { Detected bacteria } \\
(\mathrm{CFU} / \mathrm{mL})\end{array}$ & Recovery $(\%)$ \\
\hline E. coli & & \\
$10^{2}$ & $(0.898 \pm 0.071) \times 10^{2}$ & $89.8 \pm 7.1$ \\
$10^{3}$ & $(0.980 \pm 0.046) \times 10^{3}$ & $98.0 \pm 4.6$ \\
$10^{4}$ & $(0.992 \pm 0.062) \times 10^{4}$ & $99.2 \pm 6.2$ \\
$10^{5}$ & $(1.000 \pm 0.014) \times 10^{5}$ & $100.0 \pm 1.4$ \\
$10^{6}$ & $(0.974 \pm 0.013) \times 10^{6}$ & $97.4 \pm 1.3$ \\
$10^{7}$ & $(0.982 \pm 0.028) \times 10^{7}$ & $98.2 \pm 2.8$ \\
P. aeruginosa & & \\
$10^{2}$ & $(1.135 \pm 0.193) \times 10^{2}$ & $113.5 \pm 19.3$ \\
$10^{3}$ & $(1.098 \pm 0.066) \times 10^{3}$ & $109.8 \pm 6.6$ \\
$10^{4}$ & $(1.080 \pm 0.118) \times 10^{4}$ & $108.0 \pm 11.8$ \\
$10^{5}$ & $(1.004 \pm 0.125) \times 10^{5}$ & $100.4 \pm 12.5$ \\
$10^{6}$ & $(0.920 \pm 0.126) \times 10^{6}$ & $92.0 \pm 12.6$ \\
\hline
\end{tabular}


Table S2 Comparison between FORBID, Biosensor BDS1000, and Portable Fluorescent Biochemical Rapid Analyzer

\begin{tabular}{cccc}
\hline & FORBID & Biosensor BDS1000 & $\begin{array}{c}\text { ATP Portable } \\
\text { Fluorescent } \\
\text { Biochemical Rapid } \\
\text { Analyzer }\end{array}$ \\
& & & $100 \mathrm{CFU} / \mathrm{mL}$ \\
LOD & $1 \mathrm{CFU} / \mathrm{mL}$ & $10 \mathrm{CFU} / \mathrm{mL}$ & Quantitative \\
Assay procedure & One-step & One-step & Complicated \\
Sample detection & Monitor 16 & Detect one by one & Detect one by one \\
& samples & & \\
\hline & simultaneously & & \\
\hline
\end{tabular}

LOD: the limit of detection

(1) Hesari, N.; Alum, A.; Elzein, M.; Abbaszadegan, M., A biosensor platform for rapid detection of E. coli in drinking water. Enzyme Microb Tech 2016, 83, 22-28.

(2) Xu, L.; Lu, Z.; Cao, L.; Pang, H.; Zhang, Q.; Fu, Y.; Xiong, Y.; Li, Y.; Wang, X.; Wang, J.; Ying, Y.; Li, Y., In-field detection of multiple pathogenic bacteria in food products using a portable fluorescent biosensing system. Food Control 2017, 75, 21-28. 